\title{
The Relative Age of the Escarpments in the Martian Polar Laminated Terrain Based on Morphology
}

\author{
DAVID B. NASH \\ Department of Geology and Mineralogy, University of Michigan \\ Ann Arbor, Michigan 48104
}

Received December 5, 1973; revised March 1, 1974

\begin{abstract}
Three theories have been proposed to explain the morphology of large-scale topographic features seen in the Martian polar laminated terrain. These features, which are subcircular in planimetric form, appear as dark bands in wide-angle Mariner 9 frames of the polar cap. Two of the theories (by Sagan and Murray) suggest that the features are constructional, built up through deformation of thick $\mathrm{CO}_{2}$ layers or built through localized deposition of ice and dust. Another theory (Cutts) suggests the features are channels and escarpments cut into a pre-existing, featureless, layered plateau. The constructional theories suggest that the features were formed sequentially while the erosive theory suggests formation was more or less simultaneous. An experiment was performed to test whether it was possible to discern the relative age of the features.

It was assumed that if the features are constructional, continued exposure to erosional processes would change their planimetric form with time. Murray has postulated which features are oldest and which are youngest. It was found, however, that the supposed oldest features were statistically neither significantly more nor less irregular than the supposed youngest escarpments.

This evidence has led to the conclusion that the features were probably carved nearly simultaneously into a previously deposited, featureless, stratified plateau rather than being constructed sequentially.
\end{abstract}

\section{INTRODUCTION}

The Mariner 9 mission focused attention on the peculiar and unearthlike topography at the polar regions of Mars. The topography is characterized by what appear to be large, semi-circular, equator facing cliffs (or very broad asymmetric channels) with a roughly circumpolar configuration. These cliffs or channels appear to be cut into laminae that are suggestive of a depositional origin.

Some hypotheses (i.e. Murray and Malin, 1973 ; and to some extent Sagan, 1973) concerning the origin of the Martian polar topography propose that the cliffs have been formed sequentially and depositionally while another theory (Cutts, 1973b) suggests that the cliffs or channels have been carved erosively and nonsequentially. Although the relative merits of the various theories can be experimentally tested on several other points, this paper investigates

Copyright (C) 1974 by Academic Press, Inc. All rights of reproduction in any form reserved. Printed in Great Britain whether it is possible to use the Mariner 9 imagery to determine if the cliffs or channels formed sequentially or simultaneously.

\section{Topography of the Polar Regions}

Figures 1 and 2 are photographs taken by Mariner 9 of the north and south poles of Mars, respectively. Unfortunately, hard topographic data is sketchy. The way in which a researcher chooses to see the topography can greatly affect the manner in which he deciphers the history of the polar regions.

The polar terrain, with which this paper is primarily concerned, occupies most of the area poleward from $80^{\circ} \mathrm{N}$ and $-80^{\circ} \mathrm{S}$ and extends no further equatorward than $-70^{\circ} \mathrm{S}$ or $70^{\circ} \mathrm{N}$ (Cutts, 1973b). The poles are covered during the winter with a high albedo substance which recedes poleward 


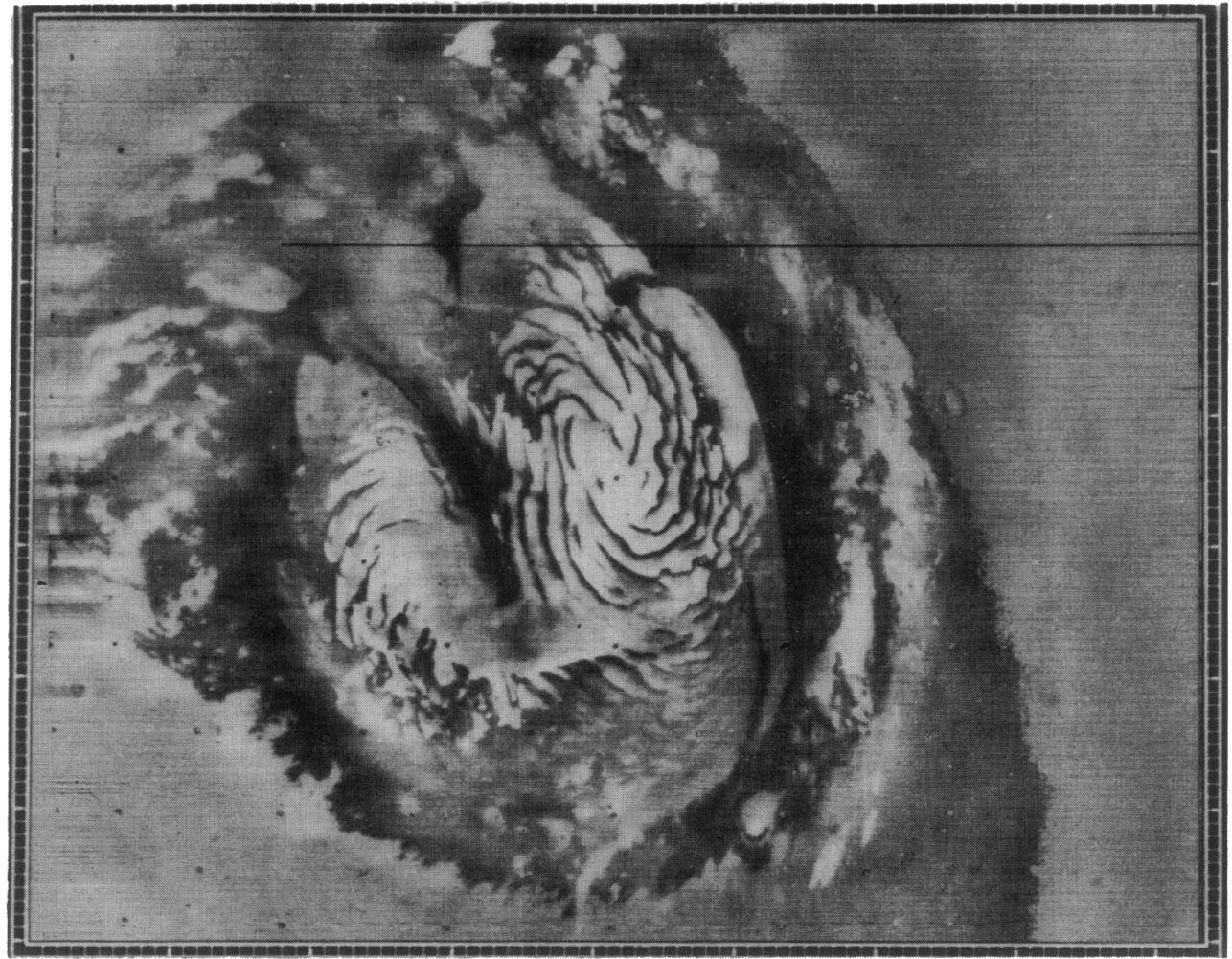

Fig. 1. The north pole of Mars showing dark bands, D.A.S. 13317550 MTVS Roll 4297 Frame 48.

during the late spring and early summer (Soderblom et al., 1973b). Spectral and radiometric measurements by Mariner 9 indicated this substance to be composed largely of solid $\mathrm{CO}_{2}$ (Murray et al., 1972). During the summer the terrain displays alternating dark and light bands of fairly uniform width (Murray et al., 1972). When the dark bands are viewed in high-resolution photography, they appear to be composed of from twenty to thirty apparently horizontal layers (Murray, 1973) from 50 to $100 \mathrm{~m}$ thick (Murray et al., 1972). Whether these dark bands represent channels or scarps cut into a laminated substance has been a source of disagreement in the various interpretations of the polar terrain. It is agreed, however, that the darkness probably results from melting of the high albedo substance on the $10-20^{\circ}$ equatorward-facing slopes (Cutts, 1973b). Due to their equatorward slope, the dark bands receive more insolation than the neighboring flat-lying light bands. It should be emphasized again that there is little evidence to support this (though it does seem reasonable).

The individual laminae making up the dark bands have been discussed extensively elsewhere (Cutts, 1973b). It has been hypothesized that they contain silicate dust or water ice or solid $\mathrm{CO}_{2}$ or a combination of these (Murray, 1973). The uniformity of thickness, number, and lateral continuity of the laminae has led some to interpret them as reflecting periodic dusty and dust-free epochs in the Martian past (Hammond, 1973). The dark slopes appear to have smooth convex-up slopes suggestive of ablation (Murray and Malin, 1973). At high resolution, the individual laminae in each dark band (particularly on the south pole) appear to have been etched into a "staircase-like" appearance suggestive of erosion (Cutts, $1973 b)$.

During the Mariner 9 mission, the area referred to as the "fork" on the south pole 


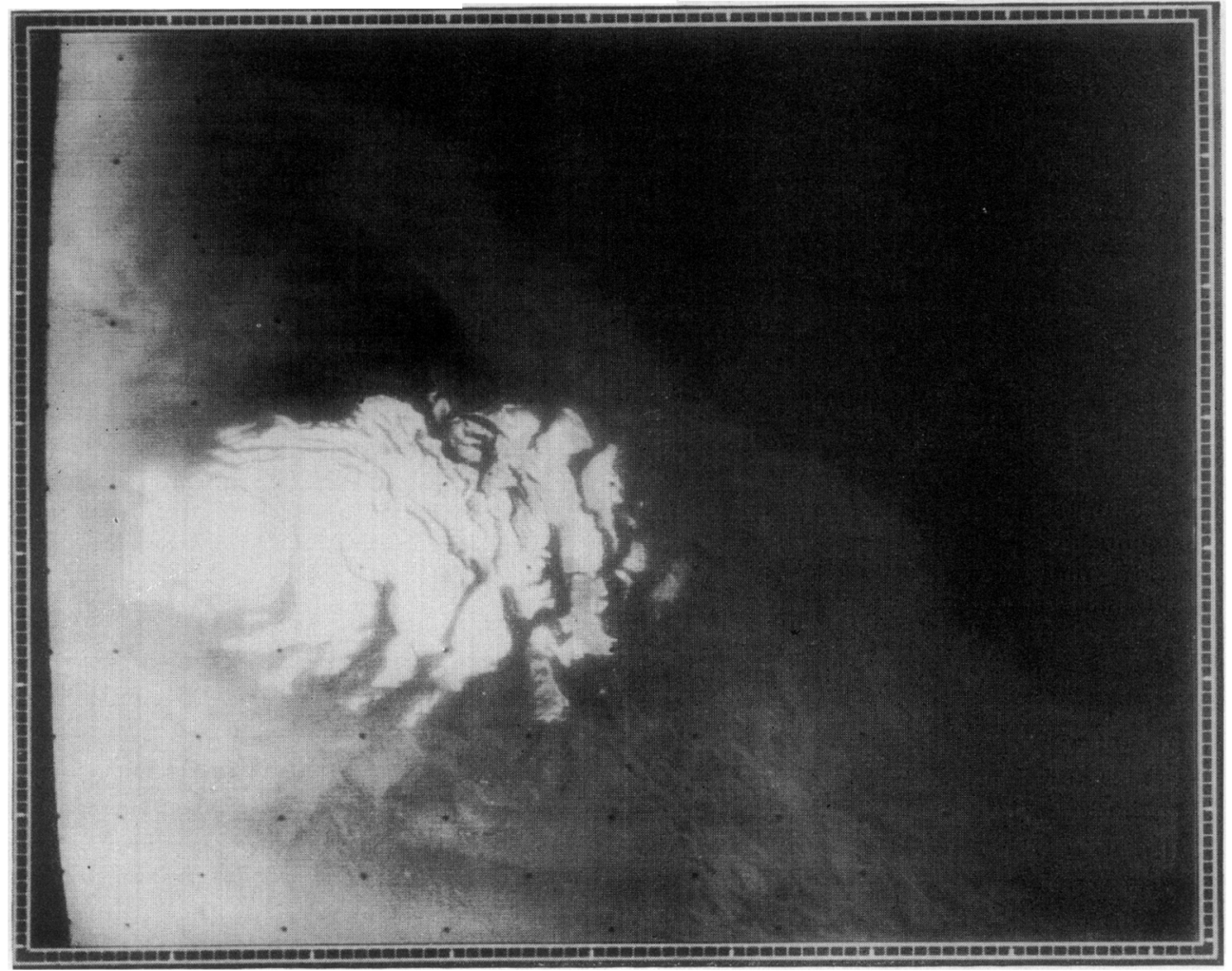

FIG. 2. The south pole of Mars showing dark bands, D.A.S. 7000738 MTVS Roll 4181 Frame 5.

was monitored at high resolution. It was seen that though the dark bands increased in width during the late spring, the poleward side of the band, according to Murray :

“. . remained remarkably stable even though other nearby concordant dark features emerged and grew in size and number as the sublimation process continued" (Murray et al., 1972).

In the following discussion, the poleward side of a dark band will be referred to as a "plate edge". It is assumed to be the upper edge of a scarp line.

\section{Current Hypotheses of the} Evolution of the Polar Topography

There are three current hypotheses that attempt to explain the nature and history of the dark- and light-banded laminar terrain on the Martian poles.
Carl Sagan (1973) has postulated that the laminated terrain is primarily composed of $\mathrm{CO}$ frost. $\mathrm{He}$ speculates that $\mathrm{CO}_{2}$ with its triple point temperature of $217^{\circ} \mathrm{K}$ and pressure of 5.1 bars cannot exist on Mars in thicknesses in excess of a few kilometers. When this depth is exceeded, the $\mathrm{CO}_{2}$ at the bottom liquefies and is squeezed outward where it refreezes (Sagan, 1973). Sagan's theory does not attempt to explain why this phenomenon should have generated the distinct laminae or why these laminae should be aggregated into distinct larger layers (the dark bands). It also does not attempt to explain why the polar deposits, particularly on the north pole, deviate substantially from circularity in plan view.

Bruce Murray interprets the topography of the laminated polar terrain as:

". . a series of stacked slightly concave plates, ... whose edges have been smoothed and modified. Individual plates perhaps 
consist of 20-40 individual laminae with an aggregate thickness on the order of a kilometer" (Murray et al., 1972).

It is proposed that the large plates (whose edges make up the dark bands) and the smaller laminae of which they are composed represent cyclical changes (of different periods) in the amount of solar insolation (differences being on the order of $10-50 \%$ ) due to changes in the obliquity of the ecliptic, eccentricity of the orbit, and the precession of the equinox. The mechanics of these changes are described elsewhere (Murray et al., 1973).

All of the above mechanisms combine to cause cyclic changes in insolation with a 51000 and a $2000000-y r$ period (Cutts, $1973 \mathrm{~b})$. It is suggested that the laminae reflect the $51000-y r$ cycle, and the larger plates reflect the $2000000-y r$ cycle. This would make the laminated terrain a relatively recent feature, a fact which Murray thinks is supported by the lack of cratering on the laminated terrain (Murray et al,, 1972). Murray explains the nonconcentric nature of the plate edges by polar wandering:

". . . the rotational axis of the planet has been displaced over the past ten millions of years as a result of convective currents deep in the mantle, currents that are probably associated with the production of volcanoes in the equatorial areas. As the spin axis has shifted, the laminated plates have formed concentrically around each successive position of the poles" (Murray, 1973).

Figures 3 and 4 are from a Murray article (Murray and Malin, 1973). They show the path Murray believed the wandering pole followed. Murray adds:

\footnotetext{
"As outlined for the Earth by Goldreich and Toomre..., the pole may be driven sequentially to different quasistationary positions in response to evolving density differences rather than exhibiting a 'spinning top' oscillatory motion" (Murray and Malin, 1973).
}

Several objections have been raised to the Murray hypothesis. Cutts says that the two-million year period Murray postulates for the formation of the plates is not long enough (according to his calculations of the current rate of deposition at the poles) (Cutts, 1973b). Cutts also suggests that the dark bands could as easily represent channels cut into the laminar terrain as being the edges of plates (Cutts, 1973b). It is pointed out that according to Murray the individual plates should be roughly circular, but in fact many of the dark

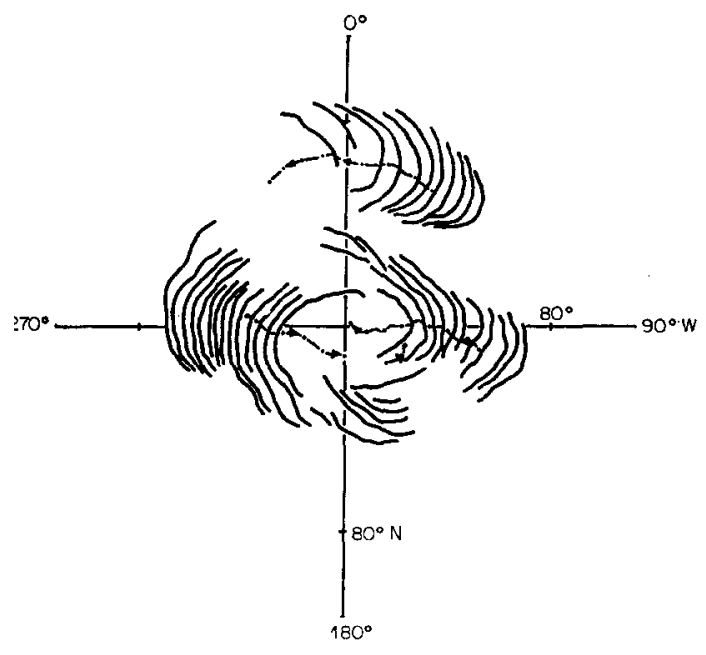

Figure 3.

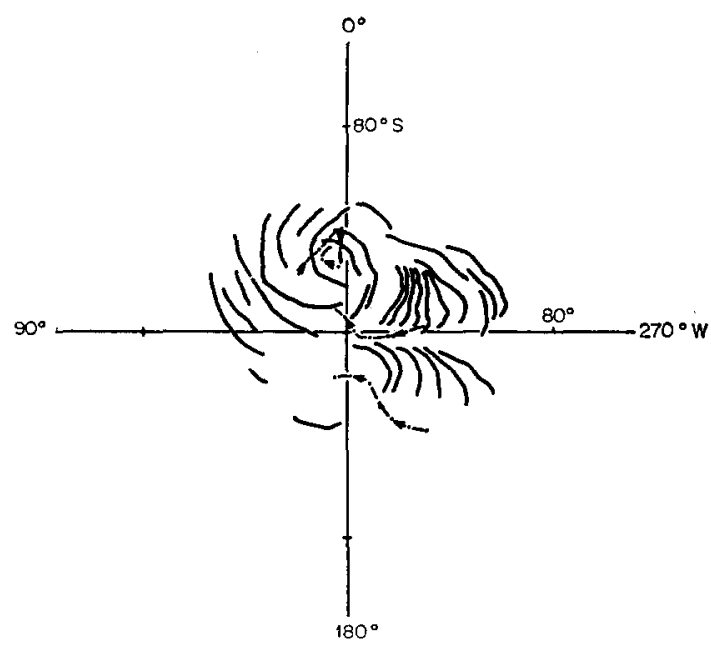

Figure 4.

Postulated paths taken by the wandering Martian pole interpreted from the position of the "plate edges" (Murray and Malin, 1973). Fig. 3. North polar stereographic projection. Fig. 4. South polar stereographic projection. 
bands are not (Cutts, 1973a). It is also evident from Figs. 3 and 4 that the paths for polar wandering on the north and south poles are not symmetrical. Cutts also disputes the observations of the planimetric form and topography reported by Murray and Malin (Cutts, 1973b) and concludes that the polar wandering theory is so geometrically confining that it could not possibly account for the great variety of topographic forms occurring in the laminated terrain.

A third hypothesis for the origin of the polar laminated terrain is presented by Cutts. Cutts postulates that the polar laminae originally accumulated in a vast, featureless, circumpolar plateau (Cutts, $1973 \mathrm{~b}$ ). The dark bands, rather than representing the edges of constructional plates, are thought by Cutts to be the sloping and terraced walls of erosional scarps and troughs. He interprets several of the small-scale features of the laminated terrain, such as pits and flutes, as wind forms. He speculates that the larger-scale pseudo-circular features were formed by air masses descending at the poles which then spiralled out from the poles due to the Coriolis effect (there is other evidence, such as the orientation of plumes of dust which have accumulated on the leeside of topographic obstructions, that suggest the present-day winds spiral outward from the pole) (Sagan et al., 1972). Cutts does not explain why the radial spiralling of the troughs is so much more marked at the north pole than at the south, nor does he explain why the winds should be confined to distinct channels.

Objections can be raised to all the current hypotheses that attempt to explain the Martian polar laminated terrain.

\section{Relative Age Dating of the Polar Escarpments}

If the Murrary hypothesis of polar wandering is accepted, the polar plates should be progressively younger in age in the direction indicated by the arrows in Figs. 3 and 4. Each plate should have taken roughly the same amount of time to form, and each should be separated by about the same time period (Murray and Malin, 1973). In order to test this hypothesis, relative-age dating of the exposed portions of the plates is needed.

The most obvious and straight-forward method of relative-age dating would be through a statistical analysis of cratering. The crater density on a surface is positively correlated with the duration of exposure of the surface. The assumptions are: (a) that the influx of meteorites has been of relatively uniform intensity and distribution; (b) that the geomorphic processes that are degrading the craters have also been of uniform intensity and distribution; and (c) that all areas are equally craterable. Unfortunately, due either to the youth, or the extreme susceptibility to erosion, or the unsusceptibility to cratering, there are few impact craters on either polar region. Craters are much too sparse to allow any statistically significant relative-age differentiation.

The abundance of what have been

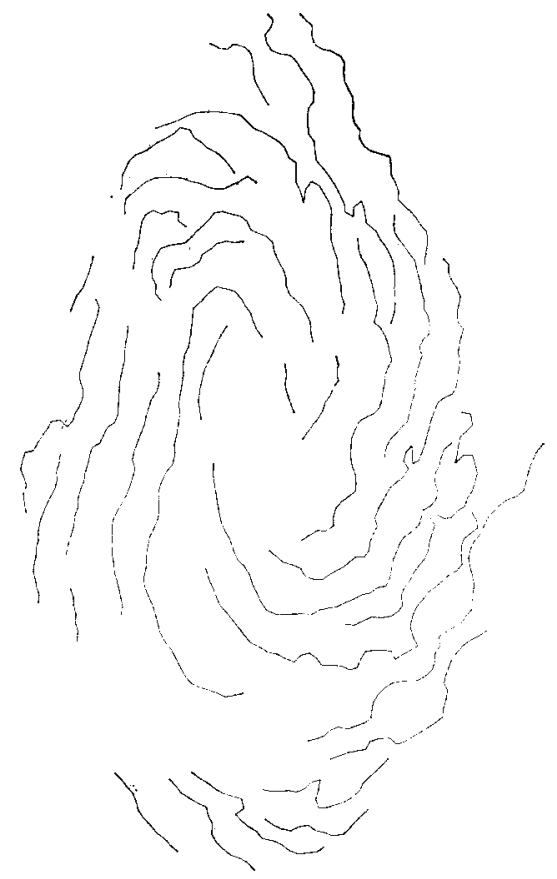

FIG. 5. North pole of Mars (with no correction for camera tilt). The dark band configuration as seen from D.A.S. 13317550 MTVS Roll 4297 Frame 48. 


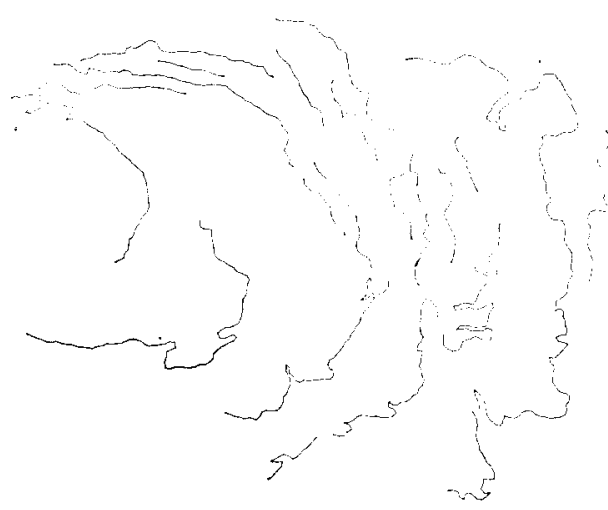

FIG. 6. South pole of Mars (with no correction for camera tilt). The dark band configurations as seen from D.A.S. 7000738 MTVS Roll 4181 Frame 5.

interpreted as eolian deflation pits presents the possibility of another way to measure the relative age of the dark-band slopes. If it is assumed the winds have been of uniform intensity geographically and that the polar surface is equally susceptible to erosion, there should be a positive correlation between both the density and mean diameter of the deflation pits and the duration of exposure of the surface. Unfortunately, the response to erosion of the laminated terrain is areally variable so

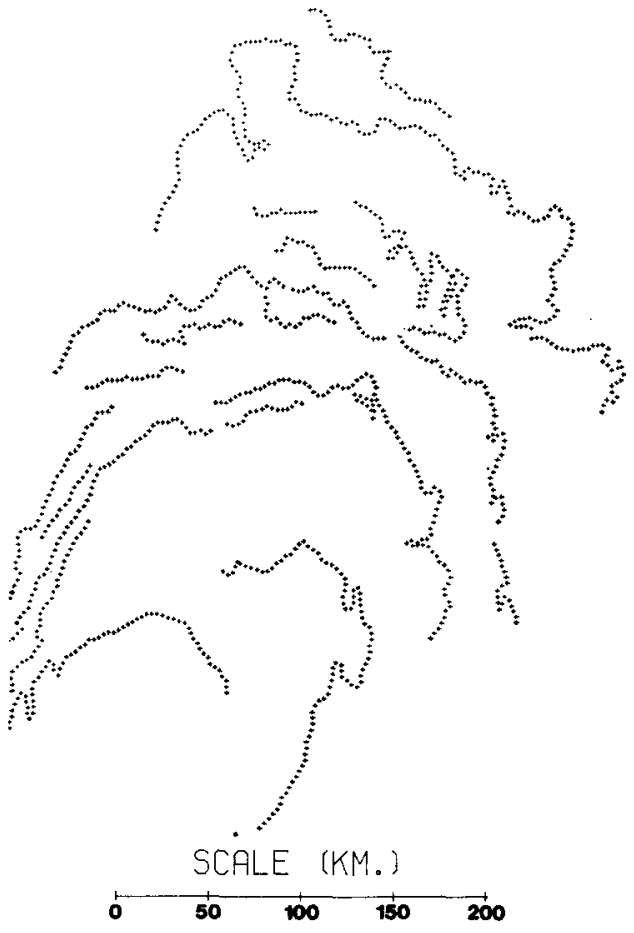

Fig. 8. South pole of Mars (corrected for camera tilt). The points used to approximate the configuration of the dark bands as seen from D.A.S. 7000739 MTVS Roll 4181 Frame 5.

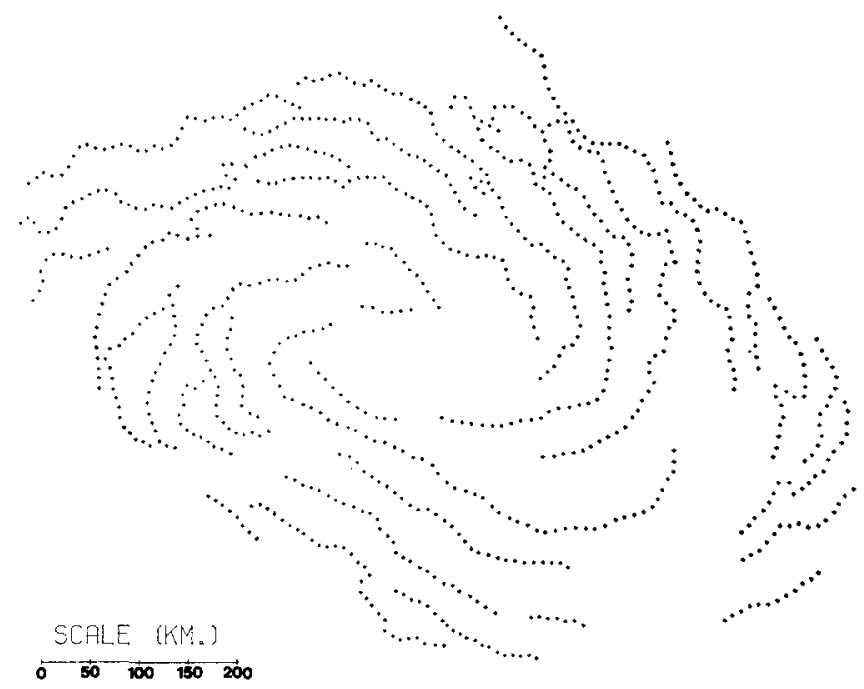

FIG. 7. North pole of Mars (corrected for camera tilt). The points used to approximate the configuration of the dark bands as seen from D.A.S. 13317550 MTVS Roll 4297 Frame 48. 
deflation pits cannot be used in the same way as are impact craters as an index of age.

A widespread, easily recognizable, and measurable phenomenon was sought that would become either more or less abundant with exposure to Martian geomorphic agents. The plate edges present such a phenomena.

It is readily apparent from Figs. 1 and 2 that the dark bands have an irregular configuration in plan view. In view of the fact that the high-resolution photography shows abundant evidence for at least eolian erosion, it seems highly unlikely that the plate edges have maintained their initial configuration without significant alteration.

It is impossible to tell whether the present irregular configuration is the result of erosive processes which attacked initially smooth circumpolar plate edges, increasing their irregularity, or whether it is the result of erosive processes "smoothing out" a formerly even more irregular configuration.

If the plate edges were originally smooth and circular in configuration, they have since become more irregular with exposure to erosion. This could occur if the plates are not uniformly resistant to erosion. The less resistant material would be selectively removed, increasing the plates irregular with time. If, on the other hand, the plate edges were originally more irregular than they are presently, they must have been smoothed out with exposure to erosion. This could occur if the erosive agents act primarily on the plate edges, as would be the case for solar ablation and if the plates were of uniform composition. The plate edge should become less irregular with continued exposure in the same way that coastal headlands of uniform composition

TABLE I

North Pole

\begin{tabular}{|c|c|c|c|c|}
\hline $\begin{array}{l}\text { Feature } \\
\text { number }\end{array}$ & $\begin{array}{l}\text { Total number of } \\
\text { points comprising } \\
\text { the feature }\end{array}$ & $\begin{array}{c}\text { Average distance } \\
\text { between two } \\
\text { adjacent points } \\
(\mathrm{km})\end{array}$ & $\begin{array}{c}\text { Average angle } \% / \mathrm{km} \\
\text { between two } \\
\text { adjacent line } \\
\text { segments }\end{array}$ & $\begin{array}{l}\text { Feature } \\
\text { roughness } \\
\text { estimator }\end{array}$ \\
\hline 1 & 12 & 10.195 & .150 & 1.489 \\
\hline 2 & 42 & 9.519 & .097 & 1.683 \\
\hline 3 & 52 & 10.250 & .234 & 1.610 \\
\hline 4 & 28 & 9.826 & .215 & .855 \\
\hline 5 & 50 & 9.877 & .099 & 1.714 \\
\hline 6 & 20 & 8.633 & .026 & .795 \\
\hline 7 & 61 & 9.649 & .067 & 1.370 \\
\hline 8 & 36 & 9.662 & .323 & 1.513 \\
\hline 9 & 56 & 10.043 & .063 & .991 \\
\hline 10 & 20 & 10.815 & .173 & 2.554 \\
\hline 11 & 14 & 10.931 & .272 & .759 \\
\hline 12 & 21 & 10.909 & .164 & 2.815 \\
\hline 13 & 27 & 10.746 & .022 & 1.387 \\
\hline 14 & 50 & 10.201 & .039 & 1.159 \\
\hline 15 & 64 & 10.508 & .202 & .540 \\
\hline 16 & 51 & 10.298 & .196 & 2.405 \\
\hline 17 & 39 & 10.276 & .457 & 3.021 \\
\hline 18 & 61 & 10.648 & .147 & .700 \\
\hline 19 & 58 & 9.602 & .191 & 3.704 \\
\hline 20 & 36 & 9.452 & .091 & 2.664 \\
\hline 21 & 32 & 9.134 & .019 & 1.553 \\
\hline 22 & 45 & 9.625 & .117 & 3.215 \\
\hline
\end{tabular}


TABLE II

South PoLE

\begin{tabular}{ccccc}
\hline Feature & $\begin{array}{c}\text { Total number of } \\
\text { points comprising } \\
\text { the feature }\end{array}$ & $\begin{array}{c}\text { Average distance } \\
\text { between two } \\
\text { adjacent points } \\
(\mathrm{km})\end{array}$ & $\begin{array}{c}\text { Average angle } \\
\text { between two } \\
\text { adjacent line } \\
\text { segments }\end{array}$ & $\begin{array}{c}\text { Feature } \\
\text { roughness } \\
\text { estimator }\end{array}$ \\
\hline 1 & 38 & 3.271 & .227 & 30.046 \\
2 & 210 & 3.330 & .201 & 34.935 \\
3 & 151 & 3.416 & .084 & $\mathbf{4 4 . 8 6 5}$ \\
4 & 14 & 2.825 & 1.070 & 26.929 \\
5 & 23 & 3.143 & .379 & 23.950 \\
6 & 76 & 3.214 & .116 & $\mathbf{2 7 . 8 9 5}$ \\
7 & 18 & 3.186 & .592 & 41.746 \\
8 & 23 & 3.152 & .290 & $\mathbf{5 0 . 2 8 4}$ \\
9 & 20 & 2.941 & .176 & 15.541 \\
10 & 43 & 3.485 & .145 & 13.126 \\
11 & 14 & 3.611 & .006 & 2.082 \\
12 & 101 & 3.275 & .171 & $\mathbf{3 4 . 8 9 3}$ \\
13 & 76 & 3.327 & .047 & 16.828 \\
14 & 32 & 3.510 & .150 & 13.452 \\
15 & 91 & 3.336 & .223 & 27.891 \\
16 & 66 & 3.240 & & 27.529 \\
\hline
\end{tabular}

become increasingly less irregular with continued exposure to strong wave action.

If the polar terrain is the result of the sequential deposition of plates, there should be an observable difference in configuration between plates of different ages.
There should be an observable trend for the plate edges to become either smoother or more irregular with time. An experiment was performed to test if it was possible to correlate configurational irregularity with the supposed age of the plate.

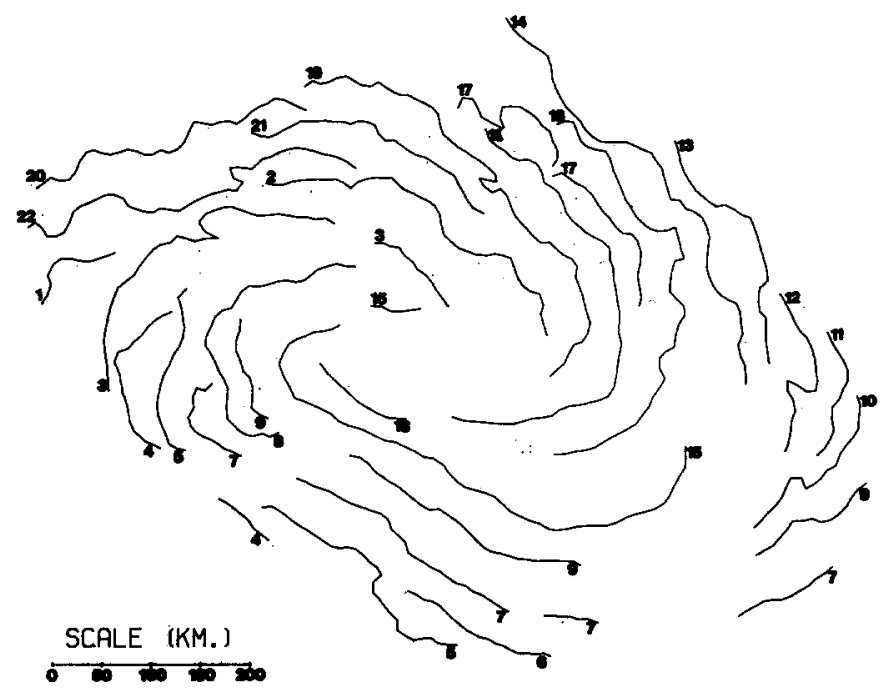

FIG. 9. North pole of Mars (corrected for camera tilt). Dark band features configuration (numbers correspond to the feature numbers alluded to in Table 1). 


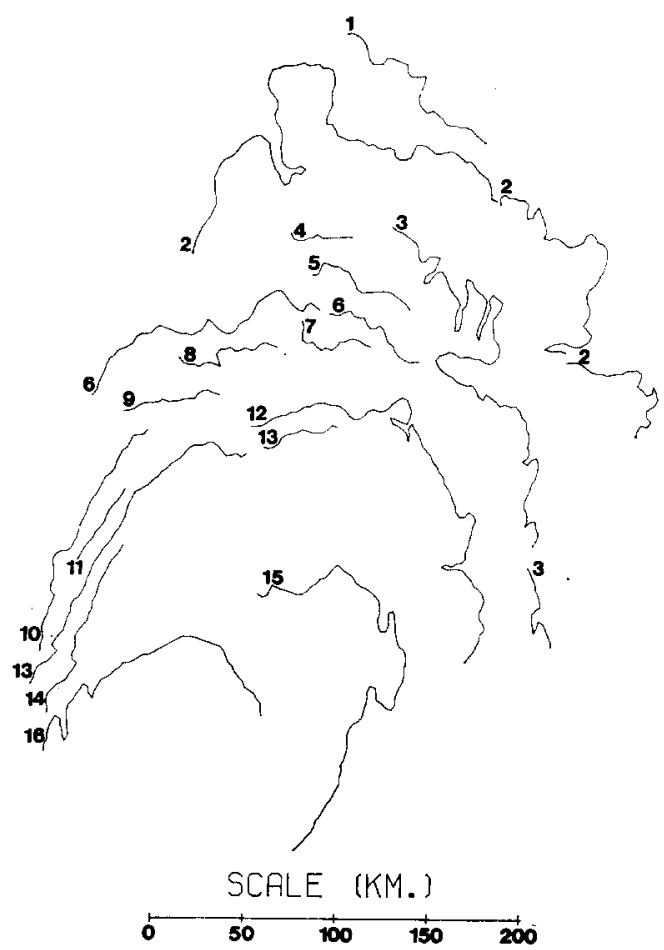

FIG. 10. South pole of Mars (corrected for camera tilt). Dark band configuration (numbers correspond to the feature numbers alluded to in Table 2).

\section{Experimental Procedure}

A completely satisfactory measure of irregularity in plan view was not found that could be applied to the plate edge. The more orthodox methods such as spatial correlation and correlation distance were unsatisfactory, because they would have necessitated the definition of the center of the circular plate. This would have been very difficult. It may even be questioned whether the plates are, or were, really circular at all. It was decided that the best method would be to approximate the configuration of each plate edge with a series of line segments of the smallest convenient length. Next, for any one plate edge, all the external angles between two adjacent line segments would be measured. A modified variance measure would be made of the external angle per kilometer for one plate edge. If the plate edge was discontinuous, the variance would be found for each of the discontinuous segments and the weighted mean would be calculated. The formula of variance that was used is :

$$
S^{2}=\frac{\sum\left(a_{i}-\bar{a}\right)^{2}}{n}
$$

where there are $n+1$ segments in the edge, $a_{i}$ is the external angle between the $i$ th and the $i$ th +1 line segments, and $\vec{a}$ is the mean external angle between adjacent line segments for that edge.

The plate edges were traced from a $32-\mathrm{cm}$ wide enlargement of D.A.S. 13317550 (north pole) and D.A.S. 7000738 (south pole) with M'TVS processing (Roll 4297 Frame 48 and Roll 4181 Frame 5). As only the clearly definable plate edges were used, there are not as many plate edges in Figs. 5 and 6 as there are in Murray's Figs. 3 and 4. For the north pole, the edges were approximated with points about $1.5 \mathrm{~mm}$ apart. The $x$ and $y$ coordinate for each point was read to the nearest tenth of a millimeter for all the points comprising the feature. The south pole was approximated with points $1 \mathrm{~mm}$ apart. The $x$ and $y$ coordinates were measured with the programmable Hewlett Packard 9820 computer equipped with a digitizer. The $x$ and $y$ coordinates were next fed into a computer and plotted with a Calcomp plotter. Figures 5 and 6 show these plots. The coordinates were then shrunk back to their original dimensions on the vidicon plate, rotated to their relative position on the planet surface implementing geometric corrections for camera tilt using the range to and the viewing angle at the center of the field of view. Figure 7 and 8 are plots of the corrected coordinates.

\section{Experimental Results}

The computer was used to calculate the variance of the external angle per kilometer for each plate edge. Tables I and II show the results of the analysis. The number of the plate edge corresponds to the number on either Figs. 9 or 10.

The linear regression of the plate edge irregularity to the plate edge number 


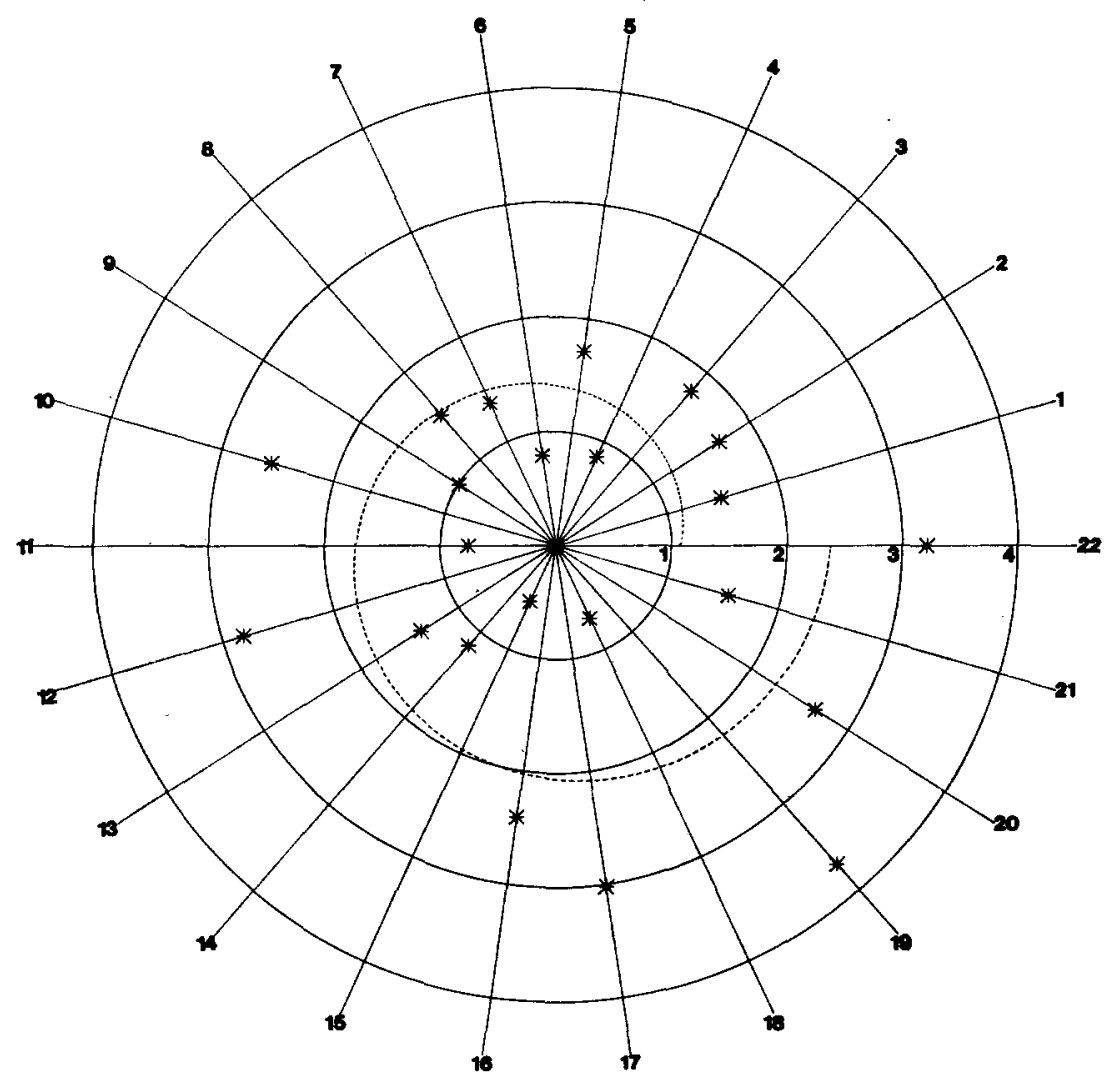

FIG. 11. North pole. Plot of dark band roughness (radial axis) against dark band number (angular axis). The numbers correspond to those used in Fig. 9 and Table 1.

presented a problem on the north pole. According to Murray, the plate edges are arranged in such a way that for any two edges the one enclosed (partially) in the concavity of the other is the younger edge. Applying this criteria to the north pole is difficult. Rather than being in a roughly concentric configuration as on the south pole, the plate edges appear to spiral out nearly radially from the geometric center of the pole. Which plate edge was formed first? It certainly isn't obvious! In order to overcome this problem, it was assumed that plate edge 1 was that edge which would yield the best least mean square fit when combined with the rest of the data. For this reason Fig. 11, a plot of "edge" irregularity to edge number, is a polar plot; the relative ordering of the plates is correct, but the assignment to any one edge of the number 1 is somewhat arbitrary. This problem was not encountered on the south pole, where the plate edges are markedly more concentric and less radial. For uniformity, the plot of irregularity to plate order number for the south pole (Fig. 12) was also done on a polar plot, even though the assignment of the first plate edge was done with a great deal more confidence.

The linear regression for plate edge order number to plate edge irregularity is drawn on the plot for each pole (Figs. 11 and 12). For the north pole the correlation coefficient was $\mathbf{. 4 2 3}$ and for the south pole -.404 .

\section{Discussion}

The lack of statistically significant changes in the planimetric irregularity among the plate edges allows at least two possible 


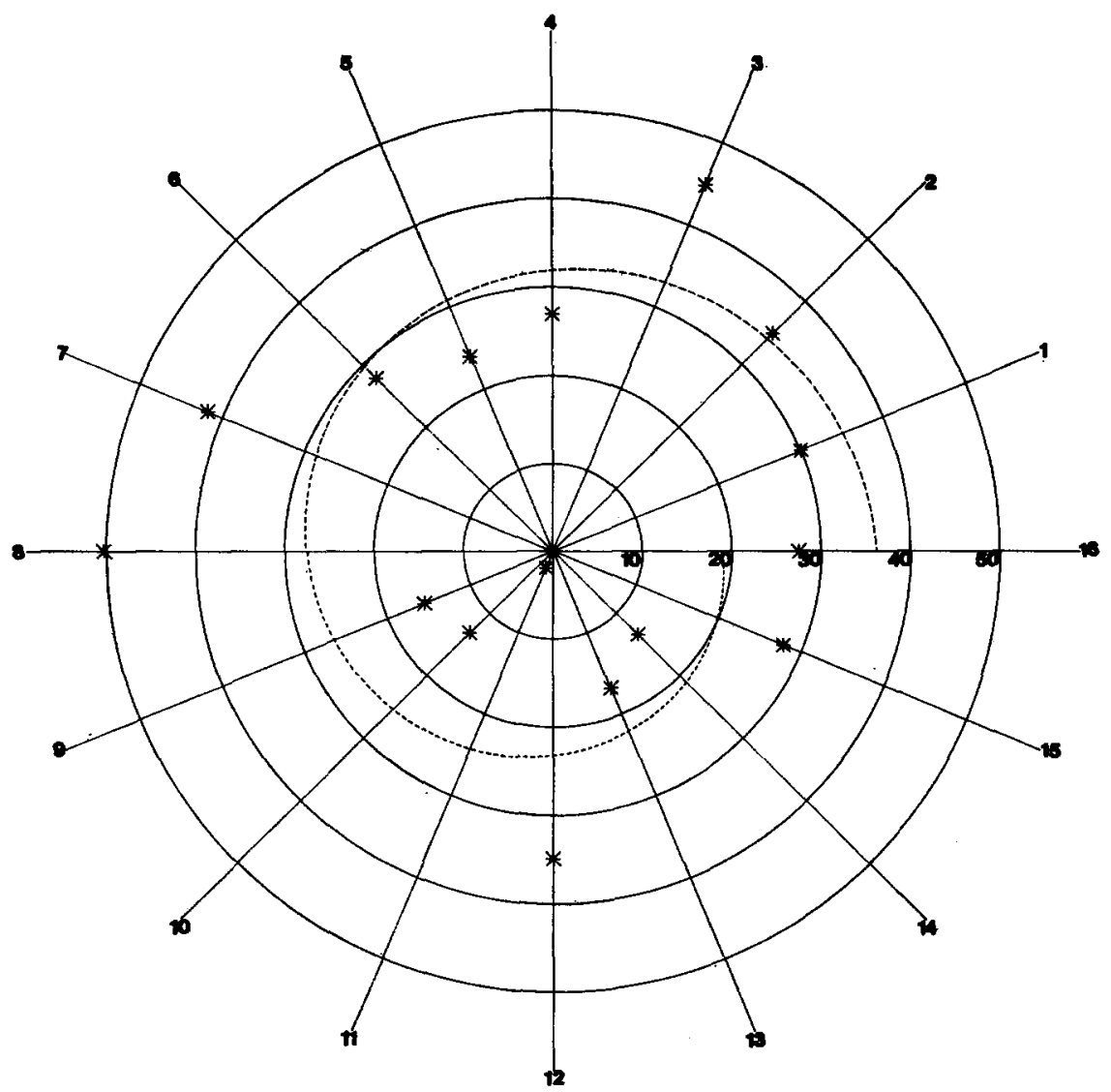

FIG. 12. South pole. Plot of dark band roughness (radial axis) against dark band number (angular axis). The numbers correspond to those used in Fig. 10 and Table 2.

conclusions: (1) the plate hypothesis is correct but the plates are now a fossil feature, with each plate having long since reached its equilibrium configuration; or (2) the polar laminated terrain is not the result of sequential deposition of circumpolar plates.

The first conclusion is possible. However, Murray has speculated that Mars has only recently begun to evolve an atmosphere through out-gassing by the Tharsis Ridge volcanoes. He cites the lack of impact cratering on the volcanoes as evidence of their youthfulness (Murray, 1973). If the plates are composed of substantial quantities of frozen volatiles, they also must be interpreted as young features. In fact, plate formation should still be active.
The second conclusion, that the sequentially deposited plate hypothesis is incorrect, appears to be quite possible.

\section{Conclusion}

This study suggests that the cliffs, channels or plate edges represented by the dark bands at the Martian poles were not formed sequentially, although it may be questioned how appropriate a dark band's irregularity in plan view is for relative-age dating of the feature. With high-resolution imagery taken under better conditions, particularly at the north pole, perhaps some other cummulative feature will be found by which the cliffs, channels or plate edges (whichever they may be) can be relatively dated. 


\section{Acknowledgments}

This research was funded by the National Aeronautic and Space Administration Grant NGR 23-005-563. The author wishes to express his gratitude to Drs. Charles I. Smith and Donald F. Eschman for their helpful and constructive criticisms. The author also thanks Cora DuBry for her help in typing this report, and Andrea Katz for her inspiration and moral encouragement.

\section{ReFerences}

Bagnold, R. A. (1941). "The Physics of Blown Sand and Desert Dunes." Chapman and Hall, London.

CaRR, M. H. (1973). Volcanism on Mars. $J$. Geophys. Res. 78 (20), 4049-4062.

Coulins, S. A. (1971). "The Mariner 6 and 7 Pictures of Mars." NASA SP-263. Washington.

Cutrs, J. A. (1973a). Wind erosion in the Martian polar regions. J. Geophys. Res. 78 (20), 4211-4221.

Cutrs, J. A. (1973b). Nature and origin of layered deposits of the Martian polar regions. J. Geophys. Res. 78 (20), 4231-4349.

Hammond, A. L. (1973). The new Mars: volcanism, water, and a debate over its history. Science 179, 463-465.

Jet Propulsion Laboratory. (1972), "The Face of Mars-Mariner 9". NASA and JPL. Pasadena, California.

Masursky, H. (1973). An overview of geological results from Mariner 9. J. Geophys. Res. 78 (20), 4009-4030.

McCauley, J. F., Carr, M. H., Cutts, J. A., Hartmann, W. K., Masursky, H., Milton, D. J., Sharp, R. P., and Wilhelms, D. E., (1972). "Preliminary Mariner Report on the Geology of Mars." United States Geological Survey Interagency Report: Astrogeology 53.
Moffit, F. H. (1967). 'Photogrammetry.' Internal Textbook Company, Scranton, Pennsylvania.

Morris, E. C., Mutch, T. A., ANd Holt, H. E. (1972). "Atlas of Geologic Features in the Dry Valleys of South Victoria Land, Antartica." United States Geological Survey Interagency Report: Astrogeology 52.

Murray, B. C. (1973). Mars from Mariner 9. Scientif. Amer. 228 (1), 4869.

Murray, B. C., and Malin, M. C. (1973). Polar wandering on Mars. Science 179, 997-1000.

Murray, B. C., Soderblom, L. A., Cutrs, J. A., Sharp, R. P., Milton, D. J., and Leighton, R. B. (1972). Geological framework of the South Polar regions of Mars. Icarus 17, 328-345.

Murray, B. C., Ward, W. R., and Yeung, Sze C. (1973). Periodic insolation variations on Mars. Science 180, 638--640.

Sagan, C., Veverka, J., Fox, P., Dubisch, R., French, R., Gierasch, P., Quam, L., Lederberg, J., Levinthal, E., Tucker, R., Eross, B., ANd Pollack, J. (1972). "Variable features on Mars II: Mariner 9 global results." J. Geophys. Res. 78, 4163-4196.

SAGAN, C. (1973). Liquid carbon dioxide and the Martian polar laminae. J. Geophys. Res. 78 (20), 4250-4251.

SNyder, L. M. (1971). "610-202 Mariner 9 T.V. Subsystem Calibration Report.” Jet Propulsion Laboratory. Pasadena, California.

Soderblom, L. A., Kreidler, T. J., AND MAsURSKY, H. (1973a). Latitudinal distribution of a debris mantle on the Martian surface. J. Geophys. Res. 78 (20), 4117-4122.

Soderblom, L. A., Malin, M. C., Cutts, J. A., AND MurRay, B. C. (1973b). Mariner 9 observations of the surface of Mars in the North Polar region. J. Geophys. Res. 78 (20), 4197-4210. 